\title{
Impact of Early Consumption of High-Fat Diet on the Mesolimbic Dopaminergic System
}

(D)F. Naneix, ${ }^{1,2, *}$ F. Tantot, ${ }^{1,3, *}$ C. Glangetas, ${ }^{1,4,{ }^{\circ}}$ (D). Kaufling, ${ }^{1,4,}{ }^{\circ}$ Y. Janthakhin, ${ }^{1,3}$ C. Boitard, ${ }^{1,3}$ V. De Smedt-Peyrusse, ${ }^{1,3}$ J. R. Pape, ${ }^{1,2}$ S. Vancassel, ${ }^{1,3}$ P. Trifilieff, ${ }^{1,3}$ F. Georges, ${ }^{1,4}$ E. Coutureau, ${ }^{1,2}$ and ${ }^{1}$ G. Ferreira $^{1,3}$

DOI:http://dx.doi.org/10.1523/ENEURO.0120-17.2017

${ }^{1}$ Université de Bordeaux, 33077 Bordeaux, France, ${ }^{2}$ CNRS, Institut de Neurosciences Cognitives et Intégratives d'Aquitaine, UMR 5287, 33077 Bordeaux, France, ${ }^{3}$ INRA, Nutrition et Neurobiologie Intégrée, UMR 1286,33077 Bordeaux, France, ${ }^{4}$ CNRS, Institut des Maladies Neurodégénératives, UMR 5293, 33077 Bordeaux, France

\section{Visual Abstract}

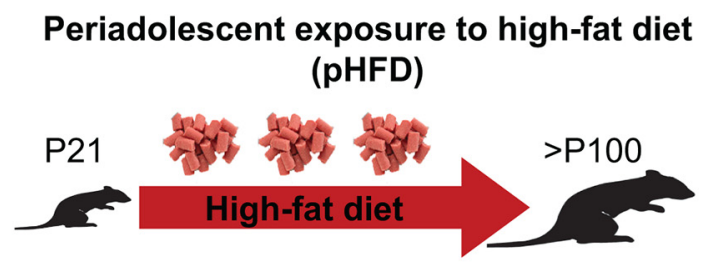

pHFD increases locomotor sensitization to amphetamine

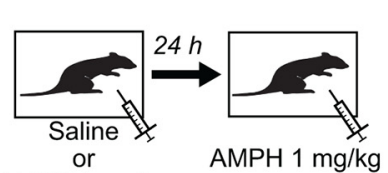

AMPH $1 \mathrm{mg} / \mathrm{kg}$

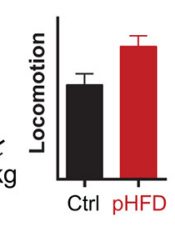

pHFD increases sensitivity of the mesolimbic DA pathway to amphetamine

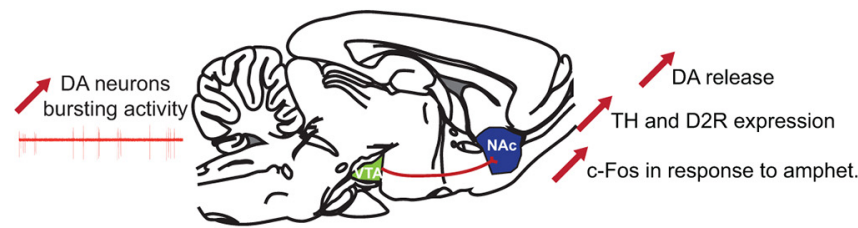

Increasing evidence suggest that consumption of high-fat diet (HFD) can impact the maturation of brain circuits, such as during adolescence, which could account for behavioral alterations associated with obesity. In the present study, we used behavioral sensitization to amphetamine to investigate the effect of periadolescent HFD exposure (pHFD) in rats on the functionality of the dopamine (DA) system, a central actor in food reward processing. pHFD does not affect responding to an acute injection, however, a single exposure to amphetamine is sufficient to induce locomotor sensitization in pHFD rats. This is paralleled by rapid neurobiological adaptations within the DA system. In pHFD-

\section{Significance Statement}

Consumption of obesogenic diet might impact the development of the reward system, leading to cognitive and behavioral alterations associated with obesity. This study investigates the effects of high-fat diet (HFD) consumption, from childhood to adulthood, on the functionality of mesolimbic dopamine (DA) system using sensitization to amphetamine. We show that a single exposure to amphetamine is sufficient to induce behavioral sensitization in HFD-exposed animals. This is associated with sensitization of the DA mesolimbic pathway, with higher bursting activity of DA neurons and enhanced DA release, greater expression of tyrosine hydroxylase (TH), D2 receptors and c-Fos levels in the NAc. This study demonstrates that early exposure to obesogenic diet consumption alters the sensitivity of DA system that may lead to reward-related disorders. 
exposed animals, a single amphetamine exposure induces an increase in bursting activity of DA cells in the ventral tegmental area (VTA) as well as higher DA release and greater expression of (tyrosine hydroxylase, TH) in the nucleus accumbens (NAc). Post-synaptically, pHFD animals display an increase in NAc D2 receptors and c-Fos expression after amphetamine injection. These findings highlight the vulnerability of DA system to the consumption of HFD during adolescence that may support deficits in reward-related processes observed in obesity.

Key words: adolescence; amphetamine; dopamine; high-fat diet; nucleus accumbens; sensitization

\section{Introduction}

Adolescence is a critical period of life characterized by major cognitive and neurobiological changes (Spear, 2000), making it a window of vulnerability to pathologic development (Andersen, 2003; Adriani and Laviola, 2004; Paus et al., 2008; Reichelt, 2016). Adolescents are particularly sensitive to rewards and often increase their consumption of palatable foods such as high-fat diet (HFD; Crews et al., 2007; Ogden et al., 2012), which could lead to obesity. The long-term consequences of chronic consumption of palatable foods during adolescence remain unclear but might lead to alterations of the brain reward system that have been associated with obesity and feeding disorders (Berthoud and Morrison, 2008; Kenny, 2011; Volkow et al., 2011; Reichelt, 2016).

The dopamine (DA) system plays a central role in incentive processes for natural and artificial rewards (Berridge and Robinson, 1998; Norgren et al., 2006; Wise, 2006; Fulton, 2010). It has been proposed that consumption of palatable foods, by increasing DA release in the nucleus accumbens (NAc; Norgren et al., 2006; Wise, 2006), could reinforce associations between environmental cues or actions with the food (Volkow et al., 2011). In both humans and rodents, numerous studies have reported enhancement of incentive processes in obese subjects or after the consumption of obesogenic diet in adults (Wang et al., 2009; Johnson and Kenny, 2010; Volkow et al., 2011; Wang et al., 2011; Robinson et al., 2015). The impact of obesogenic diet on the DA system remains unclear

Received April 8, 2017; accepted May 10, 2017; First published May 29, 2017. The authors declare no competing financial interests.

Author contributions: T.F., C.E., and F.G. designed research; T.F., N.F., G.C., K.J., J.Y., D.S.P.V., and P.J.R. performed research; T.F., N.F., J.Y., D.S.P.V., and G.F. analyzed data; N.F., T.P., C.E., and F.G. wrote the paper.

This work was supported by the following grants: Emergence de Jeune Equipe INRA 2010-2012 (to G.F.), ANR-14-CE13-0014 GOAL (to E.C., G.F.) ANR-15-CE17-0013 OBETEEN (to G.F., E.C.), ANR-10-IDEX-03-02 (to P.T.), and NARSAD Young investigator grant from the Brain and Behavior Foundation (to P.T.). F.T. was the recipient of a fellowship from the French Ministry of Research and Higher Education (2012-2015). F.N. was recipient of a postdoctoral fellowship from ANR (2015-2016).

*F.N. and F.T. contributed equally to this work

${ }^{\circ} \mathrm{C} . \mathrm{G}$. and J.K. contributed equally to this work.

Acknowledgments: We thank Mathilde Dausse for technical assistance and Mathieu Cadet and Yoan Salafranque for the care provided to the animals during the experiments.

Correspondence should be addressed to Guillaume Ferreira, Nutrition and Integrative Neurobiology (NutriNeuro), INRA 1286, Université de Bordeaux, Bâtiment UFR Pharmacie, 146 rue Léo Saignat, 33076 Bordeaux, France. E-mail: guillaume.ferreira@inra.fr.

DOI:http://dx.doi.org/10.1523/ENEURO.0120-17.2017

Copyright @ 2017 Naneix et al.

This is an open-access article distributed under the terms of the Creative Commons Attribution 4.0 International license, which permits unrestricted use, distribution and reproduction in any medium provided that the original work is properly attributed.
(Kenny, 2011; Décarie-Spain et al., 2015) and previous work reported either blunted DA activity (Davis et al., 2008; Johnson and Kenny, 2010) or increased DA response (McGuire et al., 2011; Volkow et al., 2011; Baladi et al., 2015; Fordahl et al., 2016) in response to food and drug that may both drive increased reward-seeking behaviors.

The DA system displays delayed maturation that takes place during adolescence, making it vulnerable to environmental influences (Spear, 2000; Andersen, 2003; Naneix et al., 2012; Naneix et al., 2013). Interestingly, sucrose consumption during adolescence leads to long-lasting deficits of reward processing (Frazier et al., 2008; Vendruscolo et al., 2010; Naneix et al., 2016) and HFD consumption in adolescent but not adult rats increases locomotor sensitivity to psychostimulants (Baladi et al., 2015; Fordahl et al., 2016), suggesting a particular impact of high-energy diet consumed during adolescence on the DA system (Reichelt, 2016).

In the present study, we investigated the effects of periadolescent HFD consumption (pHFD; from weaning to adulhood; Boitard et al., 2014; Boitard et al., 2015; Labouesse et al., 2016; Tantot et al., 2016) on the functionality of the mesolimbic DA system, i.e., the ventral tegmental area (VTA)-NAc pathway. For this purpose we performed behavioral sensitization to amphetamine, classically used to investigate changes in VTA-NAc DA transmission induced by repeated exposure to drugs of abuse (Robinson and Berridge, 1993; Vanderschuren and Kalivas, 2000; Steketee and Kalivas, 2011). to probe the discrete changes induced by pHFD within the DA system, but to overcome the long-lasting changes associated with the development of tolerance and dependence, we used a two-injection amphetamine protocol (Vanderschuren et al., 1999; Valjent et al., 2005; Chinen et al., 2006; Valjent et al., 2010). We demonstrate that pHFD potentiates locomotor sensitization induced by a single exposure to amphetamine. Using a multi-level approach, we then show that this behavioral effect is associated with rapid adaptations of the DA mesolimbic pathway, encompassing an increased activity of DA cells in the VTA and an enhancement of DA release, expression of DA synthesis enzyme (tyrosine hydroxylase, TH), D2 receptors and c-Fos levels in the NAc. Taken together, these data reveal the vulnerability of the DA system to HFD consumption during adolescence that may support long-term alterations of reward processing and feeding.

\section{Materials and Methods}

\section{Subjects and diet}

Male Long-Evans rats (RRID:RGD_60991; Janvier) were received at the age of three weeks and were housed by 
two in polycarbonate cages $(48 \times 26 \times 21 \mathrm{~cm})$ in a temperature $\left(22 \pm 1^{\circ} \mathrm{C}\right)$ and humidity-controlled room maintained under a normal 12/12 h light/dark cycle (lights on at 7 A.M.). The experiments took place in the light phase of the cycle. Food and water were provided ad libitum. Diets consisted in either control diet (CD, $n=101)$ providing $3.1 \mathrm{kcal} / \mathrm{g}$ [consisting of $3 \%$ lipids ( $8 \% \mathrm{kcal}$ ), $16 \%$ proteins $(19 \% \mathrm{kcal})$, and $60 \%$ carbohydrate $(73 \%$ kcal); A04, SAFE] or a HFD ( $n=119)$ providing $4.7 \mathrm{kcal} / \mathrm{g}$ [consisting of $24 \%$ lipids ( $45 \% \mathrm{kcal})$, mostly saturated fat from lard, $24 \%$ proteins $(20 \% \mathrm{kcal})$, and $41 \%$ carbohydrates (35\% kcal); D12451, Research Diets]. Rats were exposed to CD or HFD for three months from weaning (postnatal day 21) to adulthood (postnatal days 110-120). All experiments took place during adulthood. HFD consumption exceeded adolescence which is usually considered to be approximately postnatal days 30-60 in male rats (Spear, 2000; Andersen, 2003; Schneider, 2013). That is the reason why we used the term pHFD. Previous studies have shown a more pronounced cognitive and neurobiological impact of pHFD compared with similar HFD exposure starting at adulthood (Boitard et al., 2014; Boitard et al., 2015; Labouesse et al., 2016). The fact that similar HFD exposure at adulthood did not lead to similar impact discarded any acute influence of HFD intake on behavior. As we recently reported (see Table 1 in Tantot et al., 2016), male Long-Evans rats exposed to pHFD were $10 \%$ heavier than their respective controls (373 vs $336 \mathrm{~g})$ and showed significant increased levels of leptin $(+100 \%)$ and to a lesser extent of insulin and cholesterol $(+30 \%)$ but not triglycerides.

Experiments were conducted in agreement with the French (council directive 2013-118, February 1, 2013) and international legislation (directive 2010-63, September 22, 2010, European Community) and were approved (agreement number 5012047-A) by the Bordeaux Ethics Committee (CNREEA no. 50).

\section{Locomotor Activity and sensitization}

Twenty-four hours before locomotor activity testing, rats received an injection of either saline (no sensitization) or amphetamine $(1 \mathrm{mg} / \mathrm{kg}$, i.p., dissolved in $0.9 \%$ saline at $1 \mathrm{mg} / \mathrm{ml}$, Sigma Aldrich; sensitization). The day of testing, all rats first received an injection of saline and their spontaneous locomotor activity was measured during $60 \mathrm{~min}$ using individual cages $(23 \times 36 \times 19 \mathrm{~cm}$, Imetronic) equipped with two grids of photobeam sensors $(3 \times 37 \times$ $3 \mathrm{~cm}$ located at 3 and $9 \mathrm{~cm}$ above the floor). Then, rats were injected with saline (saline group; CD $n=12$, pHFD $n=16)$ or amphetamine (1 mg/kg; no sensitization CD $n=7$ and pHFD $n=9$; sensitization $\operatorname{CD} n=11$; pHFD $n=$ 17) and were then recorded for an additional $60 \mathrm{~min}$.

\section{In vivo recording of VTA-DA neurons}

Twenty-four hours after either saline 0.9\% (CD $n=5$, pHFD $n=4)$ or amphetamine ( $1 \mathrm{mg} / \mathrm{kg}$; CD $n=5$, pHFD $n=4$ ) injection in their home cage, rats were anesthetized with isoflurane. A glass micropipette (tip diameter, 2-3 $\mu \mathrm{m}$; 4-6 M $\Omega$ ) filled with a $2 \%$ pontamine sky blue solution in $0.5 \mathrm{M}$ sodium acetate was lowered into the VTA (AP $-5.3 \mathrm{~mm}, \mathrm{ML} \pm 0.7 \mathrm{~mm}$, DV $-7.5 \mathrm{~mm}$ from dura; Paxinos and Watson, 1998) as previously described (Georges and Aston-Jones, 2002). VTA-DA neurons were identified according to well established electrophysiological features (Grace and Bunney, 1983; Ungless and Grace, 2012) which included (1) action potential with biphasic or triphasic wave form $>2.5 \mathrm{~ms}$ in duration, (2) slow spontaneous firing rate $(<10 \mathrm{~Hz})$, (3) single and burst spontaneous firing patterns (characterized by spike-amplitude decrement). Signals were amplified and filtered $(0.1-5 \mathrm{kHz}$ bandpass) using conventional electronics. Single-neuron spikes were discriminated and digital pulses were led to a computer for on-line data collection with the use of a laboratory interface and software (CED 1401, SPIKE 2; Cambridge Electronic Design; RRID:SCR_000903).

Four parameters for VTA-DA neurons were analyzed: the basal firing rate, the bursting rate (number of burst events per second), the percentage of spikes that occurred in bursts (\%SIB) and the burst size (number of spikes per burst). DA neurons were also classified according to their modes of firing pattern based of firing rate and \%SIB (Mameli-Engvall et al., 2006): (1) low-frequency and low-burst firing (firing rate $<5 \mathrm{~Hz}$ and \%SIB $<20 \%$ ), (2) low-frequency and high-burst firing (firing rate $<5 \mathrm{~Hz}$ and $\%$ SIB $>20 \%$ ), (3) high-frequency and low-burst (firing rate $>5 \mathrm{~Hz}$ and \%SIB $<40 \%$ ), and (4) high-frequency and high-burst firing (firing rate $>5 \mathrm{~Hz}$ and \%SIB $>40 \%$ ). Electrophysiological recording sites were confirmed by iontophoretic deposit of pontamine sky blue dye.

\section{Microdialysis}

Twenty-four hours after either saline 0.9\% (CD $n=9$, pHFD $n=11$ ) or amphetamine (1 mg/kg; CD $n=11$, pHFD $n=10)$ injection in their home cage, rats were anesthetized with urethane $(1.5 \mathrm{~g} / \mathrm{kg}$, i.p.). A unilateral microdialysis probe (CMA 12 Elite, Phymep) was stereotaxically inserted in the NAc: AP $+1.7 \mathrm{~mm}, \mathrm{ML} \pm 1.1 \mathrm{~mm}$, DV $-7.5 \mathrm{~mm}$ from the dura (Paxinos and Watson, 1998). Artificial cerebro-spinal fluid (149 mMNaCl, $1 \mathrm{mM} \mathrm{NaH}_{2} \mathrm{PO}_{4}, 3$ $\mathrm{mMKCl}, 1 \mathrm{mM} \mathrm{MgCl}_{2}$, and $1.4 \mathrm{mM} \mathrm{CaCl}_{2}, \mathrm{pH}$ 7.4) was pumped through the probe during $1 \mathrm{~h}$ for equilibration (2.5 $\mu \mathrm{l} / \mathrm{min})$. Samples were collected every $20 \mathrm{~min}$ for $1 \mathrm{~h}$ before and $2 \mathrm{~h}$ after amphetamine injection $(1 \mathrm{mg} / \mathrm{kg}$ ) and were stored at $-80^{\circ} \mathrm{C}$ after addition of $5 \mu \mathrm{l}$ of $\mathrm{HCl}$. After the experiment, rats were sacrificed and brains were removed. Coronal sections $(50 \mu \mathrm{m})$ were collected and stained with cresyl violet to determine probe placement. Eleven rats were removed after histologic control. The final group size was: no sensitization CD $n=6$ and pHFD $n=8$; sensitization CD $n=9$ and $\operatorname{pHFD} n=8$.

The dialysate samples $(50 \mu \mathrm{l})$ were injected into a highperformance liquid chromatography equipped with a $5-\mu \mathrm{m} \mathrm{C18,} 3 \times 100 \mathrm{~mm}$ silica column (ACE, AIT) and a DECADE II detector (Antec Leyden) to quantify DA. The mobile phase, consisting of $0.1 \mathrm{M}$ citric acid, $0.1 \mathrm{M}$ dibutylamine, $0.5 \mathrm{mM}$ octanesulfonic acid, and $0.1 \mathrm{mM}$ EDTA, $\mathrm{pH} 3.5$, was pumped at $0.3 \mathrm{~mL} / \mathrm{min}$ (Dionex SA) through oxidation potential of the electrochemical detector (Decade 2, Antec) set at $600 \mathrm{mV}$. Signals were recorded and quantified with Chromeleon chromatography data system 
(Dionex SA). DA levels concentrations were calculated against a daily injected standard.

\section{DA and metabolites tissue levels}

CD $(n=10)$ or HFD $(n=17)$ naïve rats were sacrificed at adulthood and brains were quickly removed. NAc was dissected and snap-frozen before analysis. Tissue levels of DA and metabolites (DOPAC) were quantified by HPLC-ED as previously described (Parrot et al., 2011).

\section{c-Fos immunostaining}

Twenty-four hours after amphetamine sensitization, rats received a second injection of either saline $0.9 \%$ (CD $n=5$, pHFD $n=5)$ or amphetamine ( $1 \mathrm{mg} / \mathrm{kg}$; CD $n=4$; pHFD $n=5$ ) in their home cage. Ninety minutes later, rats were sacrificed with an overdose of pentobarbital sodium and perfused transcardially with $0.1 \mathrm{M}$ PBS $(\mathrm{pH} 7.4)$, followed by $4 \%$ paraformaldehyde in PBS. Brains were postfixed overnight in $4 \%$ paraformaldehyde and then transferred in $30 \%$ sucrose PBS solution for $48 \mathrm{~h}$. Finally, brains were frozen in isopentane and stored at $-80^{\circ} \mathrm{C}$. Coronal sections $(40 \mu \mathrm{m})$ were generated on a cryostat and incubated in blocking solution (PBS, Triton X-100 $0.3 \%$, BSA $3 \%$ ) for $45 \mathrm{~min}$, then with primary anti c-Fos antibody (1:1000 in blocking solution; Santa Cruz Biotechnology; RRID:AB_2106783) for $24 \mathrm{~h}$ at $4^{\circ} \mathrm{C}$. After rinses, sections were then incubated in $\mathrm{PBS}-\mathrm{H}_{2} \mathrm{O}_{2} 0.3 \%$ for $30 \mathrm{~min}$, rinsed, and incubated with secondary antibody (biotinylated donkey anti-rabbit 1:2000; Jackson ImmunoResearch; RRID:AB_2340593) for $2 \mathrm{~h}$ at room temperature. They were then incubated with avidin-biotin-peroxydase complex (1:1000; Vector Laboratories) for $1 \mathrm{~h}$ at room temperature. The staining was revealed after 10-min incubation in a mix of diaminobenzidine, ammonium chloride, ammonium sulfate, sodium acetate, glucose and glucose oxydase. The reaction was stopped by incubation in sodium acetate $(2 \times 10 \mathrm{~min})$. c-Fos labeling was quantified bilaterally on three sections spaced $240 \mu \mathrm{m}$ apart and chosen to cover the NAc and the medial prefrontal cortex according to the Paxinos and Watson atlas (Paxinos and Watson, 1998). Each section was photographed using Nikon-ACT-1 software, and labeled cells were counted with ImageJ software (RRID:SCR_003070) on a surface representing $1 \mathrm{~mm}^{2}$.

\section{Western blotting}

Twenty-four hours after either saline $0.9 \%(C D n=11$, pHFD $n=10)$ or amphetamine $(1 \mathrm{mg} / \mathrm{kg}$; (CD $n=11$, pHFD $n=11$ ) injection in their home cage, rats were killed and brain regions were manually dissected, frozen in dry ice and stored at $-80^{\circ} \mathrm{C}$ before analysis. For the analysis of DA receptors, two pHFD rats were removed due to the absence of signal (no sensitization $n=9$; sensitization $n=$ 10). Tissue samples were lysed in $300 \mu \mathrm{l}$ of extraction buffer respectively containing $50 \mathrm{mM}$ Tris, 2\% SDS, $5 \mathrm{M}$ urea, and phosphatase/protease inhibitor cocktail (Thermo Fisher) and were sonicated (amplitude $80 \%, 4 \times 1$ s) on ice. Protein contents were determined by the MicroBCAssay (Uptima, Interchim) according to the manufacturer's protocol. For DA transporter (DAT), TH, and D1R detection, $5 \mu \mathrm{g}$ of protein, diluted in $2 \times$ Laemmli buffer, were heated for 5 min at $75^{\circ} \mathrm{C}$ and loaded on a $4-15 \%$ polyacrylamide gradient gel (D1556, Bio-Rad). For D2R, $10 \mu \mathrm{g}$ of protein diluted in $2 \times$ Laemmli buffer were loaded on $12 \%$ acrylamide gel. Proteins were transferred on nitrocellulose membrane (Protran Premium 0.2 $\mu \mathrm{m}$, GE Healthcare) using a Miniprotean system (Bio-Rad). Membranes were saturated with $5 \%$ fatfree dry milk in TBS-Tween $0.1 \%$ for $1 \mathrm{~h}$ at room temperature and probed overnight at $4^{\circ} \mathrm{C}$ with primary antibodies: DAT (1:1000, AB2231, Millipore; RRID:AB_1586991), D1R (1: 1000, D2944, Sigma Aldrich; RRID:AB_1840787), TH (1: 5000, MAB318, Millipore; RRID:AB_2313764) and D2R (kindly provided by Prof. J. Javitch, Columbia University). Anti- $\beta$-actin (1:2500, Biolegend; RRID:AB_315945) or antiGAPDH (1:5000, Cell Signaling Technolology; RRID:AB_ 10622025) antibodies were used against internal markers to normalize protein expression. Primary antibodies were detected with appropriated donkey horseradish peroxidase-conjugated secondary antibodies (1:5000, Jackson ImmunoResearch). The blots were developed by using Supersignal Westdura (Thermo Fisher). Specific protein signals were quantified by measuring chemiluminescence with Chemidoc Detection System and Image Lab Software (Bio-Rad).

\section{Statistical analysis}

Statistical analyses were conducted using GraphPad Prism 6 (RRID:SCR_002798). Data were analyzed using two-tailed Student's $t$ test or ANOVA with or without repeated measures when appropriate, followed by Bonferroni's post hoc tests. Normality was checked with the Shapiro-Wilk test. As electrophysiological parameters did not follow a normal law (except firing rate), nonparametric tests were used (Kruskall-Wallis and Mann-Whitney $U$ tests). The $\alpha$ risk for rejection of the null hypothesis was fixed at 0.05 .

\section{Results}

\section{pHFD increases amphetamine-induced locomotor sensitization}

The behavioral effect of pHFD on the functionality of the mesolimbic DA system was first investigated using locomotor response and sensitization to amphetamine. $C D$ or pHFD-exposed rats received a first injection of saline (no sensitization) or amphetamine (1 mg/kg; sensitization; Fig. 1). Twenty-four hours later, their locomotor activity was first measured during $60 \mathrm{~min}$ in response to an injection of saline. pHFD did not affect basal locomotor activity of nonsensitized (CD: $792 \pm 71 /$ pHFD: $887 \pm 57 ; t_{(30)}=1.1$, $p=0.2$ ) and sensitized rats (CD: $910 \pm 61 /$ pHFD: $767 \pm$ $\left.54 ; t_{(42)}=1.7, p=0.09\right)$. In accordance with these results, nonsensitized CD and pHFD groups responded similarly to a second injection of saline (diet: $F_{(1,26)}=3.5, p=0.07$; time: $F_{(6156)}=19.9, p<0.001$; interaction: $F_{(6156)}=0.7$, $p=0.6$; Fig. $1 A$ ) or to a first injection of amphetamine, which similarly increased locomotor activity in $C D$ and pHFD rats (diet: $F_{(1,14)}=1.2, p=0.3$; time: $F_{(6,84)}=8.9$, $p<0.001$; interaction: $F_{(6,84)}=0.63, p=0.7$; Fig. $\left.1 B\right)$. Interestingly, pHFD sensitized rats displayed higher locomotor activity in response to a second injection of amphetamine compared with CD rats (diet: $F_{(1,42)}=6.2, p=$ 
A

SAL-induced locomotor activity No sensitization

Activity cage
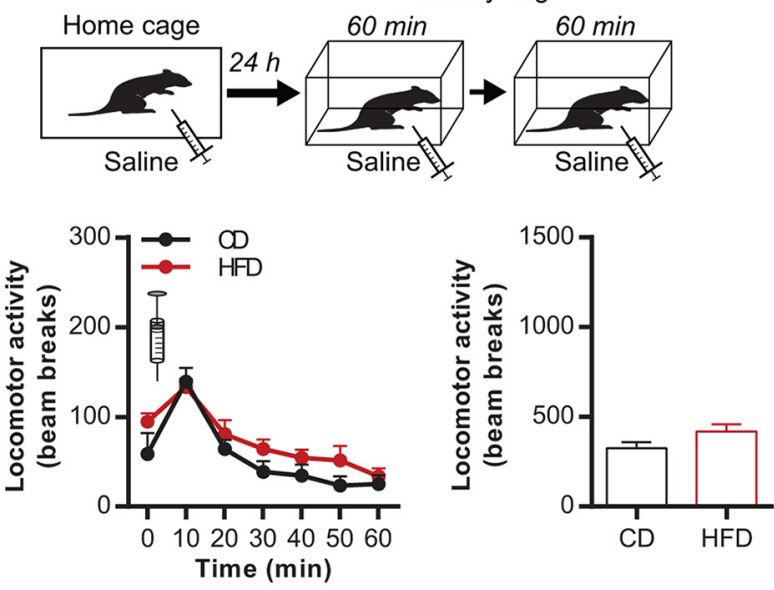

B

AMPH-induced locomotor activity No sensitization

Activity cage
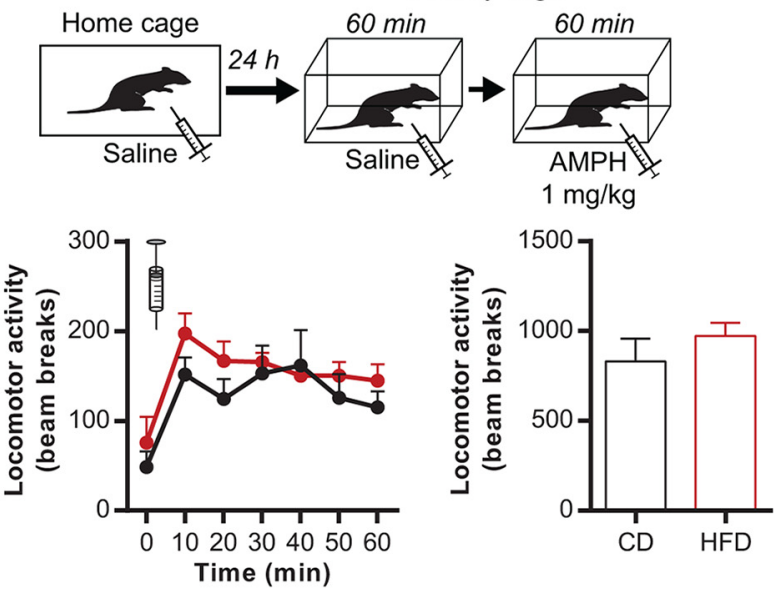

C

AMPH-induced locomotor activity Sensitization
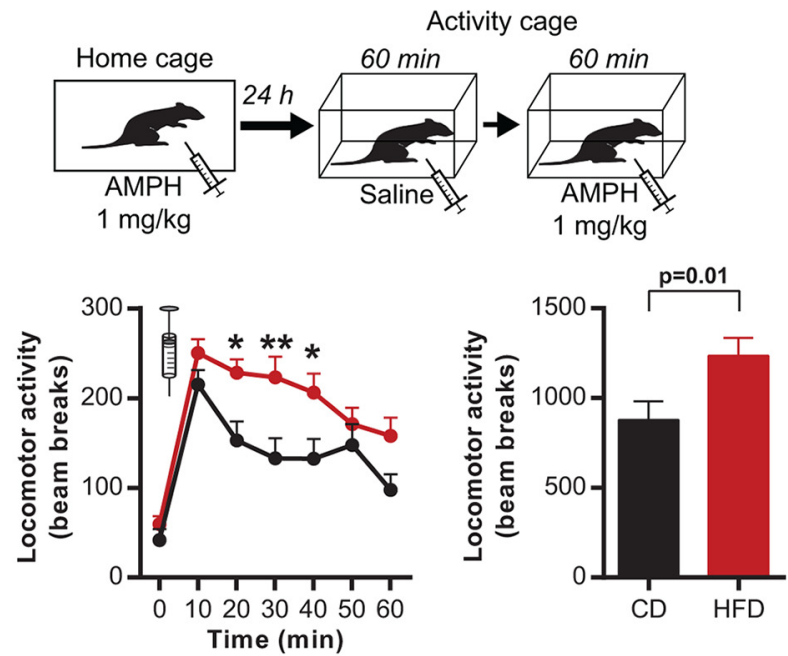

Figure 1. pHFD increases amphetamine-induced locomotor sensitization. A, Locomotor activity (photobeam counts) in response to saline was not affected by pHFD in nonsensitized
Figure 1. continued

animals (CD $n=12$; pHFD $n=16$ ). $\boldsymbol{B}$, Locomotor activity in response to amphetamine was not affected by pHFD in nonsensitized animals (CD $n=7$; pHFD $n=9$ ). $\boldsymbol{C}$, pHFD diet increased locomotor activity in response to amphetamine in sensitized animals (CD $n=11$; pHFD $n=17$ ). Left panels, Locomotor activity every $10 \mathrm{~min}$. Right panels, Cumulative locomotor activity during $60 \mathrm{~min}$. Syringes represent the time of amphetamine injection. Data are expressed as mean + SEM. $* p<0.05, * * p<$ 0.01 diet effect.

0.01; time: $F_{(6252)}=41.4, p<0.001$; interaction: $F_{(6252)}=$ 2.6, $p<0.1$; Fig. 1C). Comparison of sensitized and nonsensitized animals indicated a tendency toward a more sustained locomotor activity in pHFD sensitized rats (time $\times$ sensitization interaction: $F_{(6198)}=1.9, p=0.08$; Fig. $1 B, C)$ which was not observed in CD rats. These results demonstrated that $\mathrm{pHFD}$ rats sensitize faster than $C D$ rats suggesting that periadolescent obesogenic diet might increase the reactivity of the DA system at adulthood.

\section{pHFD increases activity of DA mesolimbic pathway after amphetamine sensitization}

Because the VTA-NAc DA pathway plays a central role in locomotor response to drugs and behavioral sensitization (Vanderschuren and Kalivas, 2000; Ungless et al., 2001; Steketee and Kalivas, 2011), we next evaluated the impact of pHFD on the electrophysiological activity of VTA DA cells in anesthetized rats $24 \mathrm{~h}$ after saline or amphetamine administration (Fig. 2A,B). All groups exhibited a similar number of spontaneously active DA neurons per electrode track suggesting that neither pHFD nor amphetamine sensitization affected the population activity in the VTA (Kruskal--Wallis test; $K_{(3)}=1.6, p=0.6$; Fig. $2 C$ ). In nonsensitized rats, pHFD did not alter firing rate or bursting activity (Fig. 2D-G), demonstrating that HFD did not affect DA neurons functioning under basal conditions. Prior amphetamine sensitization significantly increased firing rate in both $\mathrm{CD}(+19 \%)$ and $\mathrm{pHFD}$ rats $(+35 \%$; diet $F_{(1115)}=0.1, p=0.7$; sensitization: $F_{(1115)}=6.4, p<0.05$; interaction: $F_{(1115)}=0.4, p=0.5 ;$ Fig. $\left.2 D-E\right)$. Interestingly, sensitization induced a significant increase of bursting rate specifically in pHFD animals (Kruskal--Wallis test followed by Mann--Whitney $U$ test; $K_{(3)}=7.1, p=0.07$; diet effect: no sensitization $U=372, p=0.8$; sensitization $U=344, p<0.05$; sensitization effect: $C D U=475, p=$ 0.9; HFD $U=260, p<0.05$; Fig. $2 F, G)$, without affecting other parameters such as the \%SIB or the number of spikes per burst $\left(K_{(3)}=3.3, p=0.3\right.$ and $K_{(3)}=4.5, p=$ 0.2 , respectively; Fig. $2 H$ ). Furthermore, despite the changes in both firing and bursting of DA neurons after sensitization, a more detailed analysis reported a similar distribution of firing patterns between CD and pHFD rats $\left(\chi^{2}\right.$ test; no sensitization: $\chi^{2}=3.9, p=0.3$; sensitization: $\chi^{2}=1.5, p=0.7$; Fig. $2 /$ ). Taken together, these results demonstrate that pHFD sensitizes to amphetamine-induced increase in bursting activity of VTA DA cells. 
A

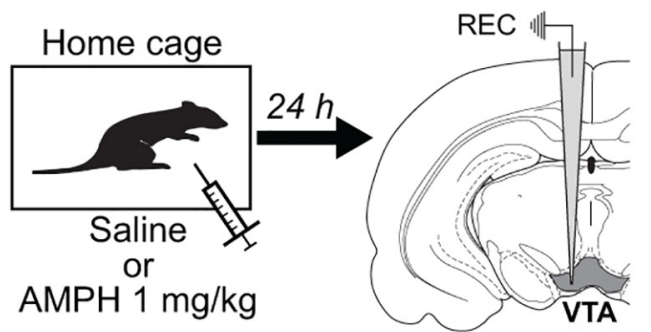

B

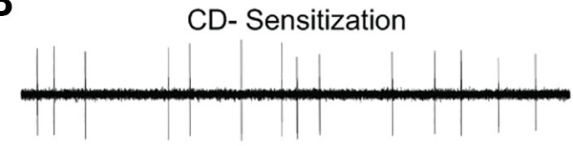

HFD- Sensitization
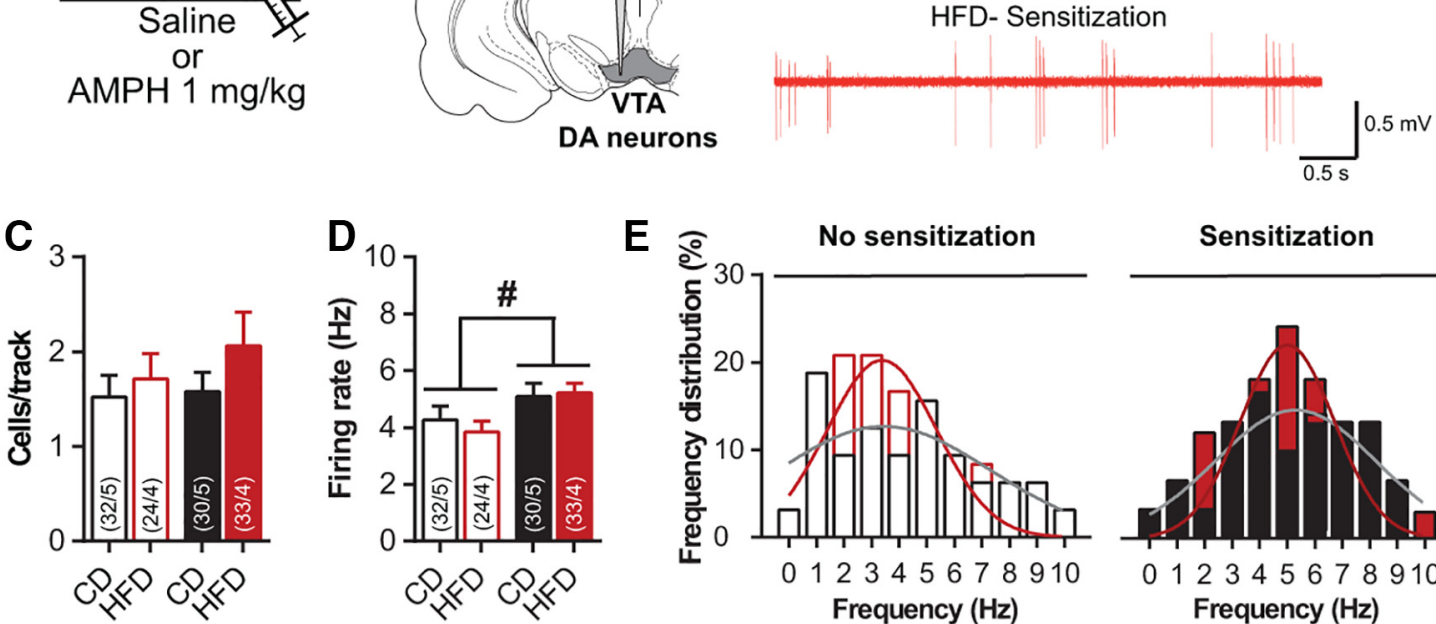

E

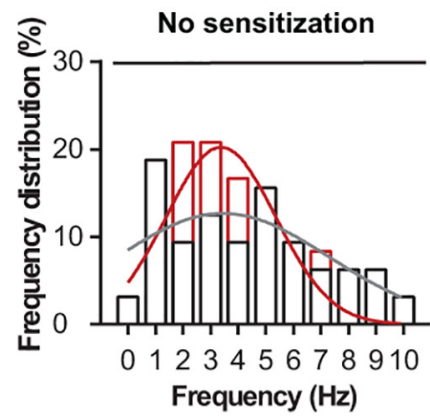

Sensitization

No sensitization

Sensitization
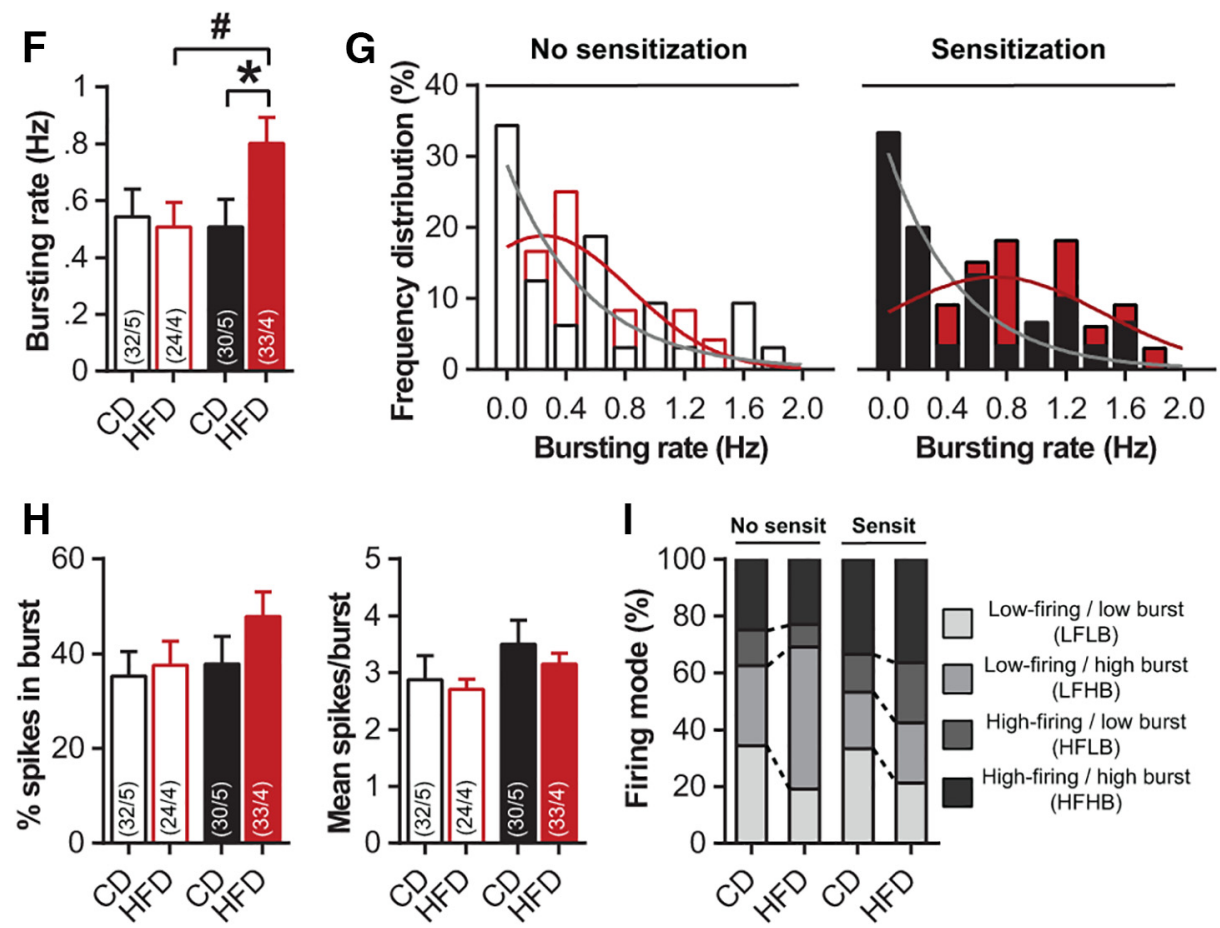

Figure 2. Amphetamine sensitization increases bursting activity of VTA-DA neurons after pHFD. $\boldsymbol{A}$, Experimental schematic: $24 \mathrm{~h}$ after saline or amphetamine injection, VTA-DA neurons were recorded on anesthetized rats (no sensitization: CD $n=5$ and pHFD $n=4$; sensitization CD $n=5$ and pHFD $n=4$ ). $\boldsymbol{B}$, Representative traces of VTA putative DA neurons for CD (top) and pHFD (bottom) groups $24 \mathrm{~h}$ after amphetamine injection. $\boldsymbol{C}$, Number of spontaneously active DA neurons in the VTA is not affected by pHFD or amphetamine sensitization. $\boldsymbol{D}$, Firing rate of VTA-DA neurons was not affected by pHFD but was increased by amphetamine sensitization. $\boldsymbol{E}$, Distribution of VTA-DA neurons firing rate was not affected by pHFD (Kolmogorov-Smirnov test; no sensitization: $D_{(56)}=0.19$, $p=0.6$; sensitization: $D_{(63)}=0.18, p=0.7$ ) but was right-shifted by amphetamine sensitization (CD: $D_{(62)}=0.21, p=0.4$; HFD: $\left.D_{(57)}=0.36, p=0.05\right)$. $\boldsymbol{F}$, Amphetamine sensitization increased the bursting rate of VTA-DA neurons only in pHFD rats. $\boldsymbol{G}$, Distribution of VTA-DA neurons bursting rate was shifted toward high frequency in pHFD sensitized animals (Kolmogorov-Smirnov test; no sensitization: $D_{(56)}=0.17, p=0.8$; sensitization: $D_{(63)}=0.35, p<0.05 ; \mathrm{CD}: D_{(62)}=0.18, p=0.6 ; \mathrm{HFD}: D_{(57)}=0.34, p=0.07$ ) $\boldsymbol{H}, \%$ SIB and burst size were not changed by pHFD or amphetamine sensitization. $\boldsymbol{I}$, Firing modes patterns are not affected by pHFD. Numbers in bars indicate the number of cells and rats. Solid lines in $\boldsymbol{E}$, $\boldsymbol{G}$ represent the best-fit distribution curve for the histogram data. Data are expressed as mean + SEM. $* p<0.05$ diet effect; $\# p<0.05$ sensitization effect. 
A

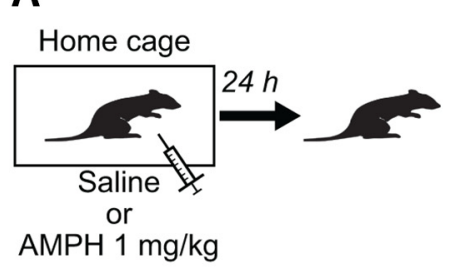

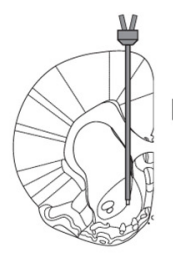
anesthetized rats
DA microdialysis on

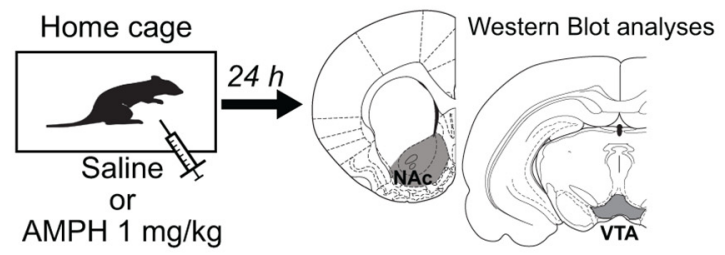

No sensitization

Baseline Amphetamine

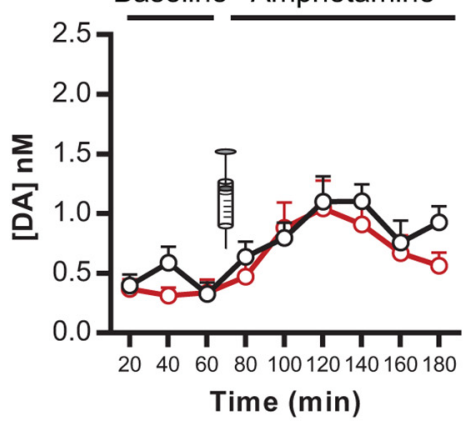

B

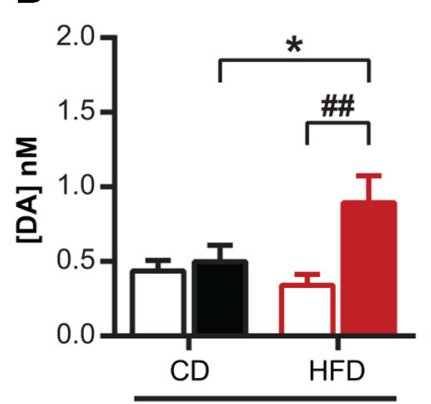

Baseline
Sensitization

Baseline Amphetamine
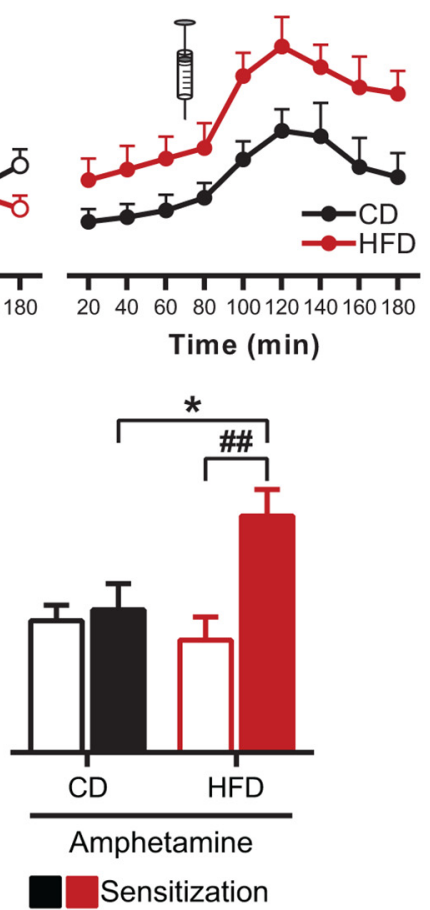

C Basal Tissue levels of DA and metabolites
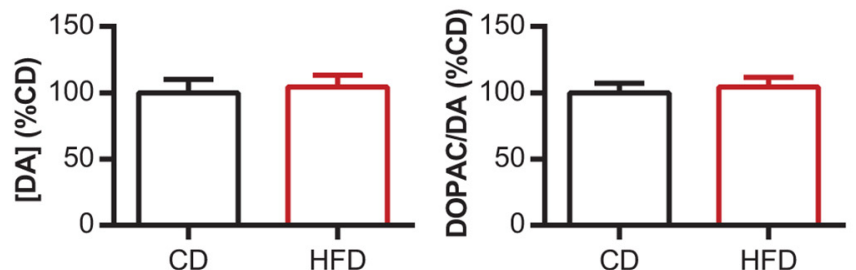

Tyrosine hydroxylase (TH)

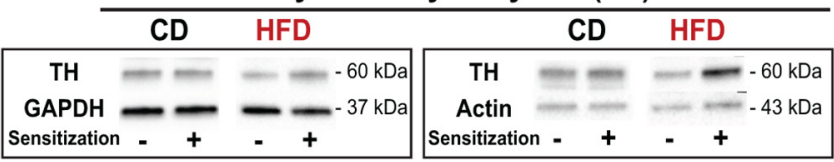

VTA

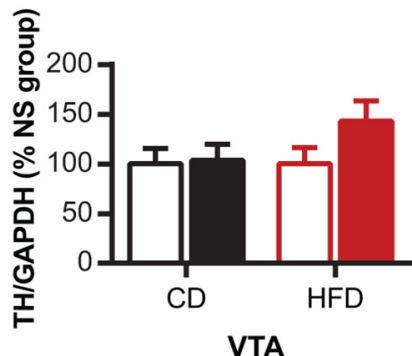

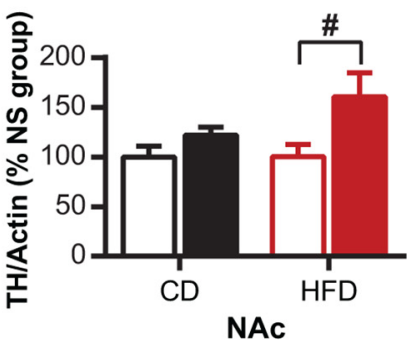

NAC

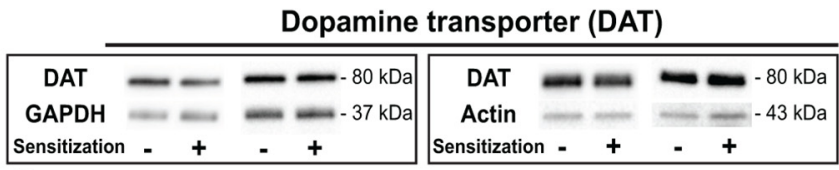

Sensitization - +-+
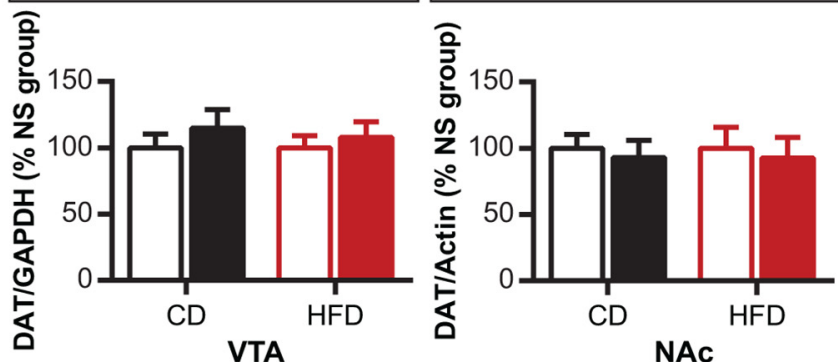

No sensitization

Sensitization

Figure 3. Amphetamine sensitization increases DA release and TH expression in the NAc after pHFD. $\boldsymbol{A}$, pHFD rats showed an increase in NAc DA release after amphetamine sensitization but not before (no sensitization CD $n=6$ and $p H F D n=9$; sensitization $\mathrm{CD} n=9$ and pHFD $n=8$ ). Syringes represent the time of amphetamine injection. $\boldsymbol{B}$, Amphetamine sensitization increased NAc DA release only in pHFD group at both basal state and in response to a second injection of amphetamine. $\boldsymbol{C}$, Basal tissue levels of DA (left) and DOPAC-to-DA ratio (right) in the NAc was not altered by pHFD in nonsensitized rats (data are expressed in \% of CD; CD $n=$ 10 and pHFD $n=17)$. $\boldsymbol{D}$, Amphetamine sensitization increased expression of TH in the NAc and the VTA but did not affect DAT expression (data are expressed in \% of respective nonsensitized group; no sensitization CD $n=11$ and $\operatorname{pHFD} n=10$; sensitization $\mathrm{CD} n=11$ and pHFD $n=11$ ). Data are expressed as mean + SEM. $* p<0.05$ diet effect; \#p $<0.05$, \#\#p $<0.01$ sensitization effect.

The activity of VTA DA cells is directly related to DA release in the NAc (Floresco et al., 2003) which is a central structure for behavioral sensitization processes (Vanderschuren and Kalivas, 2000; Ikemoto, 2002). In accordance with locomotor activity (Fig. 1), nonsensitized CD and
pHFD groups displayed similar basal and amphetamineinduced DA levels assessed by microdialysis (diet: $F_{(1,12)}=0.7, p=0.4$; time: $F_{(8,96)}=10.3, p<0.001$; interaction: $F_{(8,96)}=0.7, p=0.7$; Fig. $3 A$, left). This absence of diet effect was confirmed, at basal state, by 
Table 1. Effect of pHFD on the expression of DA markers in the NAc and the VTA of nonsensitized rats

\begin{tabular}{|c|c|c|c|c|c|c|}
\hline & NAc & & & VTA & & \\
\hline & Mean \pm SEM & Student's $t$ test & $p$ value & Mean \pm SEM & Student's $t$ test & $p$ value \\
\hline $\mathrm{TH}$ & $\begin{array}{l}\text { CD: } 100 \pm 8 \\
\text { HFD: } 95 \pm 12\end{array}$ & $t_{(19)}=0.4$ & $p=0.7 ; \mathrm{NS}$ & $\begin{array}{l}\text { CD: } 100 \pm 13 \\
\text { HFD: } 63 \pm 11\end{array}$ & $t_{(19)}=2.1$ & $p<0.05 ; *$ \\
\hline DAT & $\begin{array}{l}\text { CD: } 100 \pm 10 \\
\text { HFD: } 100 \pm 10\end{array}$ & $t_{(19)}=0.004$ & $p=0.9 ; \mathrm{NS}$ & $\begin{array}{l}\text { CD: } 100 \pm 12 \\
\text { HFD: } 100 \pm 10\end{array}$ & $t_{(19)}=0.01$ & $p<0.9 ; \mathrm{NS}$ \\
\hline D1R & $\begin{array}{l}\text { CD: } 100 \pm 11 \\
\text { HFD: } 106 \pm 7\end{array}$ & $t_{(18)}=0.4$ & $p=0.6 ; \mathrm{NS}$ & & & \\
\hline D2R & $\begin{array}{l}\text { CD: } 100 \pm 11 \\
\text { HFD: } 104 \pm 12\end{array}$ & $t_{(18)}=0.2$ & $p=0.8 ; \mathrm{NS}$ & & & \\
\hline
\end{tabular}

Expression levels of TH, DAT and DA receptors (D1R and D2R). All data are expressed as mean \pm SEM and in $\%$ of CD group. NS, nonsignificant; $* p<0.05$ diet effect.

similar DA concentration $\left(t_{(25)}=0.8, p=0.4\right)$ and DOPAC/DA ratio $\left(t_{(25)}=0.05, p=0.9\right)$ in NAc tissue (Fig. $3 C$ ) as well as similar NAc expression of the DAT and the rate-limiting enzyme in DA synthesis $\mathrm{TH}$ (Table 1).

Consistent with our behavioral results, amphetamine sensitization induced an increase in DA levels only in pHFD-exposed rats at both basal state and in response to a second amphetamine injection [diet: $F_{(1,15)}=6.7, p<$ 0.05 ; time: $F_{(8120)}=14.9, p<0.001$; interaction: $F_{(8120)}=$ $0.7, p=0.7$ (Fig. $3 A$, right); diet: $F_{(1,27)}=1.7, p=0.2$; sensitization: $F_{(1,27)}=7.1, p<0.05$; Block: $F_{(1,27)}=39.9$, $p<0.001$; diet $\times$ sensitization: $F_{(1,27)}=4.7, p<0.05$; interaction diet $\times$ block: $F_{(1,27)}=0.2, p=0.6$; interaction sensitization $\times$ block: $F_{(1,27)}=0.6, p=0.4$; interaction diet $\times$ sensitization $\times$ block: $F_{(1,27)}=0.5, p=0.5$ (Fig. $3 B)]$. Consistently, this increase was associated, in the pHFD group, with a higher TH expression in the NAc (CD: $+21 \%, t_{(20)}=1.6, p=0.1$; HFD: $+60 \%, t_{(19)}=2.1, p<$ $0.05)$ and a trend in the VTA (CD: $+4 \%, t_{(20)}=0.2, p=$ 0.8 ; HFD: $\left.+42 \%, t_{(19)}=2.2, p=0.1\right)$ without changes in DAT expression (all $t<0.8, p>0.4$; Fig. 3D). These results show that pHFD intake enhances the effect of amphetamine sensitization on the DA mesolimbic system by increasing VTA activity and NAc DA release.

\section{pHFD increases postsynaptic cellular changes in the NAc after amphetamine sensitization}

Behavioral sensitization is mediated through the recruitment of NAc DA receptors leading to postsynaptic neuronal activity as revealed by the induction of c-Fos expression (Graybiel et al., 1990; Konradi et al., 1996; Valjent et al., 2005). To evaluate whether the increased response to amphetamine in pHFD rats also triggers postsynaptic changes in the NAc, we first measured c-Fos expression, 90 min after saline or amphetamine injection focusing on sensitized animals (Fig. 4A,B). As expected, amphetamine injection induced higher NAc c-Fos expression than saline injection in both groups. Strikingly, sensitized pHFD animals showed an overall significant higher level of NAc c-Fos than CD rats whatever the type of injection (diet: $F_{(1,15)}=6.8, p<0.05$; drug: $F_{(1,15)}=14.7$, $p<0.01$; interaction: $F_{(1,15)}=0.9, p=0.4$; Fig. $4 C$ ) demonstrating increased neuronal activity in the NAc of pHFD animals following amphetamine exposure. This pattern of c-Fos expression was not observed in the medial prefrontal cortex (all $F<0.8, p>0.4$; Fig. $4 C$ ), suggesting the mesoaccumbens DA pathway is more vulnerable to pHFD than the mesocortical DA pathway.

We next measured the expression of the DA receptors D1R and D2R in the NAc. Western blot analyses revealed no differences between CD and pHFD groups in basal condition (Table 1). A single injection of amphetamine 24 $\mathrm{h}$ before was sufficient to enhance the expression of D2R $(+36 \%)$ compared with nonsensitized pHFD rats, which was not observed on CD animals (+5\%; CD: $t_{(20)}=0.2$, $p=0.8$; HFD: $t_{(17)}=2.4, p<0.05$; Fig. $4 D$ ). No significant changes were observed for the expression of D1R for both CD and pHFD groups (all $t<1.4, p>0.2$ ).

\section{Discussion}

The results of the present study reveal that chronic HFD from childhood to adulthood induces long-term alterations in the sensitivity of the DA mesolimbic pathway. Strikingly, using a short sensitization protocol (Valjent et al., 2005; Chinen et al., 2006; Valjent et al., 2010), we revealed that $\mathrm{pHFD}$ potentiates amphetamine-induced sensitization and adaptations of the VTA-NAc DA system. Previous studies have already shown a higher response to drug sensitization after obesogenic diet using a variety of diet conditions and psychostimulants (McGuire et al., 2011; Baladi et al., 2015; Robinson et al., 2015; Fordahl et al., 2016; Oginsky et al., 2016). However, we demonstrate here that a single drug-induced stimulation of the DA system in HFD-exposed animals is sufficient to induce behavioral and neurobiological adaptations, stressing the vulnerability of the DA mesolimbic system to HFD consumption.

We first report similar basal locomotor activity and response to a single amphetamine injection between CD and pHFD-exposed rats. Consistent with this behavioral pattern, pHFD did not affect DA cells activity, levels of DA and metabolites, DAT, TH, or DA receptors expression, suggesting a normal functioning of DA system before challenge, as supported by previous studies conducted in adult animals exposed to obesogenic diet (Décarie-Spain et al., 2015). By contrast to our results, however, several studies in human and animal models have reported that diet-induced obesity decreases the basal expression of striatal DA receptors D2R (Wang et al., 2009; Johnson and Kenny, 2010; Wang et al., 2011; Robinson et al., 2015; Friend et al., 2016). Such a discrepancy likely results from 
A

\section{Sensitization of AMPH-induced c-Fos expression}

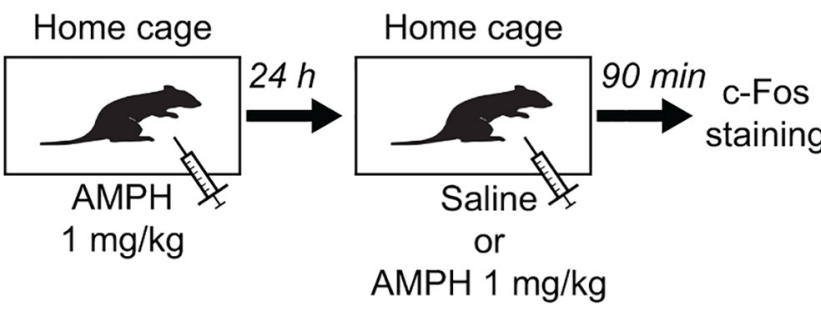

B

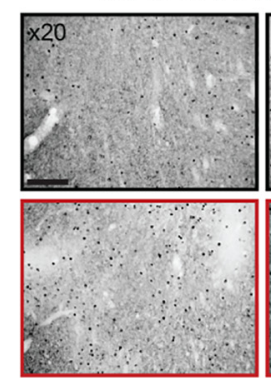

Saline
CD

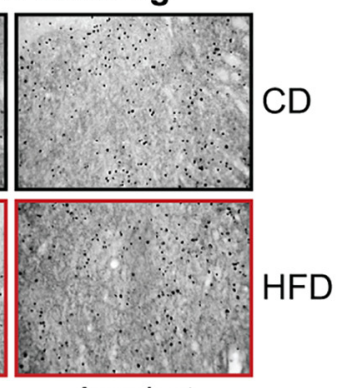

Amphet
C

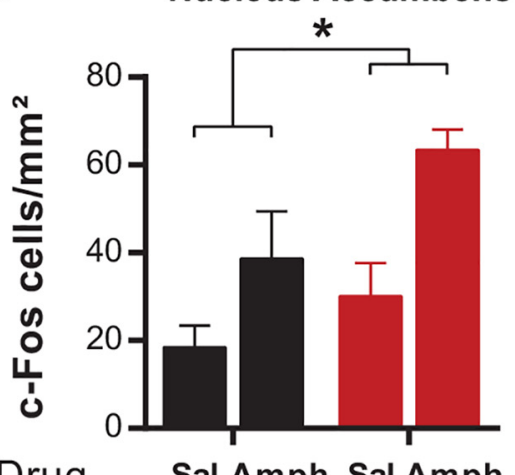

\section{Prefrontal cortex}

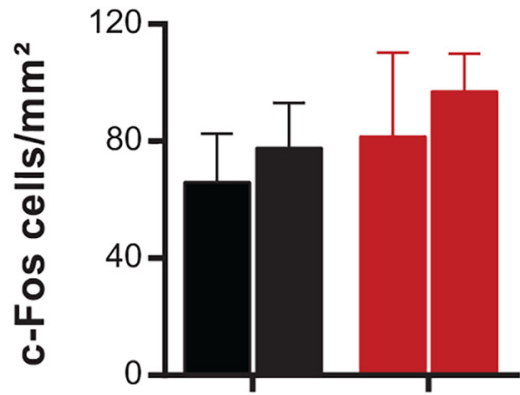

Sal Amph Sal Amph Drug $\square C D$ $\square$ HFD

D

Drug

Sal Amph Sal Amph

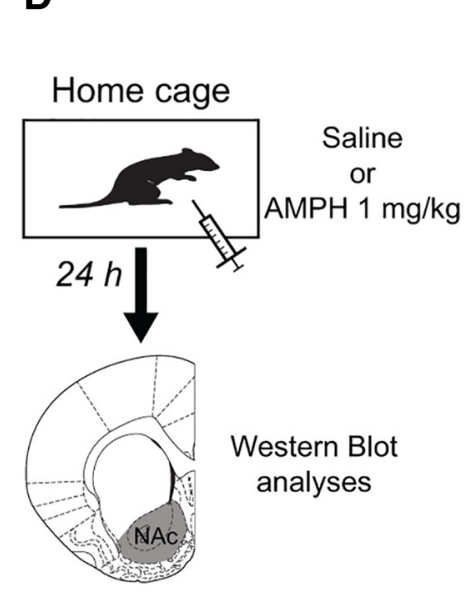

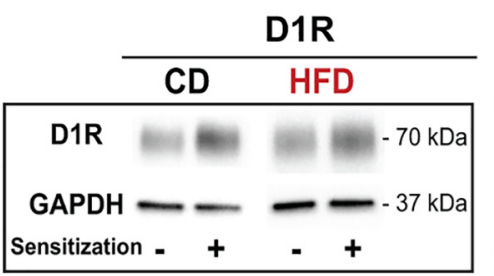

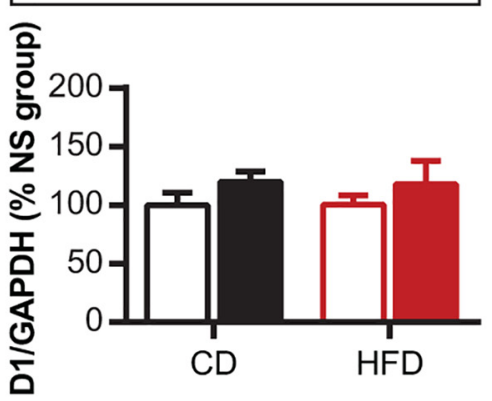

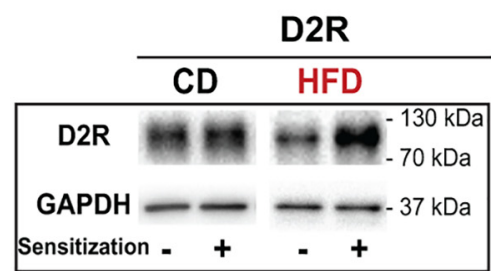

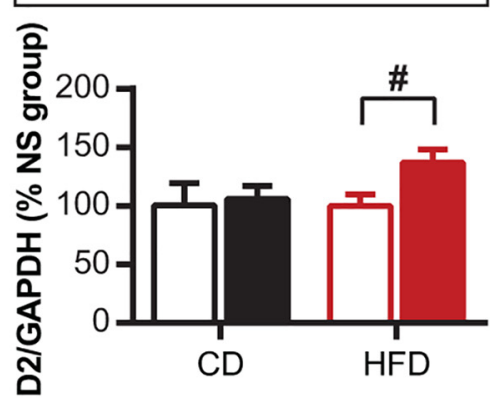

$\square$ No sensitization

Figure 4. Amphetamine sensitization increases c-Fos expression and D2R expression in the NAc after pHFD. $\boldsymbol{A}$, Twenty-four hours after amphetamine injection, rats were perfused $90 \mathrm{~min}$ after an intraperitoneal injection of either saline (CD $n=5$; $\mathrm{pHFD} n=5)$ or amphetamine $(C D n=4 ;$ pHFD $n=5)$. B, Representative pictures of c-Fos immunostaining in NAc for each experimental group at high magnification $(20 \times)$. Scale bar, $100 \mu \mathrm{m}$. C , Sensitized pHFD rats had more c-Fos levels in the NAc than CD animals, independently of saline or amphetamine injection but not in the prefrontal cortex $(n=4-5)$. $\boldsymbol{D}$, Amphetamine sensitization increased expression of D2R in the NAc (data are expressed in \% of respective nonsensitized group; no sensitization $\mathrm{CD} n=11$ and $\mathrm{pHFD} n=9$; sensitization $\mathrm{CD} n=11$ and pHFD $n=10)$ but did not affect D1R expression. Data are expressed as mean + SEM. $* p<0.05$ diet effect; \#p $<0.01$ sensitization effect.

the moderate weight gain in HFD-fed rats in the present study as it was recently stressed that weight gain (influenced by the composition, the duration and the feeding pattern of the obesogenic diet) represents an important factor determining the impact of HFD intake on DA system (Décarie-Spain et al., 2015).

In the present study, since we aimed at investigating subtle changes in DA functioning, we used a two-injection 
protocol with low dose of amphetamine. Using this procedure, our results show that control rats did not increase their locomotor activity to the second amphetamine injection, a result which is consistent with previous research. Indeed, under such two-injection protocol, it has been repeatedly demonstrated that behavioral sensitization to psychostimulants depends on both the delay between drug exposures and the relative contextual similarity between the first and the second drug injection (Robinson and Berridge, 1993; Vanderschuren et al., 1999; Vanderschuren and Kalivas, 2000; Chinen et al., 2006; Steketee and Kalivas, 2011). The pattern of results obtained in pHFD animals was in contrast with the CD animals since they show an increased locomotor activity following the second drug administration, therefore demonstrating behavioral sensitization. Our results show that this behavioral effect might be related to changes in the sensitivity of the mesolimbic system as discussed below.

In the present study, pHFD-sensitized animals displayed an increased bursting activity of VTA DA cells. Behavioral sensitization involves complex interactions between glutamatergic and DA transmission (Graybiel et al., 1990; Konradi et al., 1996; Vanderschuren and Kalivas, 2000), even after a single exposure to drugs (Valjent et al., 2005; Valjent et al., 2010). Bursting activity of DA cells is highly controlled by glutamatergic excitatory inputs in the VTA (Georges and Aston-Jones, 2002; Floresco et al., 2003; Glangetas et al., 2015) that are quickly potentiated by drug exposure (Ungless et al., 2001). Since the consumption of palatable food already strengthens excitatory transmission on DA cells (Liu et al., 2016), it is possible that a single amphetamine injection is sufficient, in pHFD rats, to potentiate glutamatergic inputs on VTA DA cells, increasing their bursting activity. This increased activity of DA cells combined with the higher NAc TH expression in sensitized pHFD rats could likely participate to their higher NAc DA release that could, in turn, be responsible for the increased locomotor activity in response to amphetamine through the recruitment of postsynaptic DA receptors (Campbell et al., 1997; Heusner et al., 2003).

In striatal regions, postsynaptic $\mathrm{D} 1 \mathrm{R}$ and $\mathrm{D} 2 \mathrm{R}$ are mainly expressed by GABAergic medium spiny neurons (MSNs) segregated into two distinct output pathways, D1R-MSNs and D2R-MSNs (Le Moine and Bloch, 1995), which have functionally opposing effects on locomotion (Gerfen and Surmeier, 2011; Kravitz et al., 2012; Cui et al., 2013). Previous research in lean animals have demonstrated the critical involvement of D1R, but not D2R, in drug-induced striatal expression of c-Fos and locomotor sensitization (Graybiel et al., 1990; Konradi et al., 1996; Valjent et al., 2005; Valjent et al., 2010). Surprisingly, sensitized pHFD rats displayed up-regulation of NAc D2R, but not D1R. However, recent studies indicate that D2RMSNs could also participate in locomotor sensitization. Inhibition of D2R-MSNs, mimicking DA action on D2R, does not change acute locomotor responses to amphetamine, but increases amphetamine sensitization (Ferguson et al., 2011). This effect seems to involve suppression of lateral inhibition exerted by D2R-MSNs on D1R-MSNs in the NAc (Dobbs et al., 2016). We therefore hypothesize that the higher DA release in sensitized pHFD rats induces greater NAc c-Fos levels through both the direct D1R stimulation as well as stronger disinhibition of D1R-MSNs due to D2R upregulation.

In summary, our study provides evidences that the chronic consumption of HFD during periadolescent period enhances the sensitivity of the mesolimbic DA system. Adolescence represents a key period of vulnerability to the effects of HFD on brain function (Noble and Kanoski, 2016; Reichelt, 2016). Interestingly, we recently showed that memory alterations induced by pHFD can be reversed by shifting HFD to CD (Boitard et al., 2016). However, protracted alterations of the mesolimbic DA system and reward-based processes were reported after the removal of adolescent HFD/high-sugar diet, suggesting different sensitivities of brain circuits to deleterious effects of palatable foods (Teegarden et al., 2009; Vendruscolo et al., 2010; Carlin et al., 2016; Naneix et al., 2016). Moreover, we previously demonstrated in rats that HFD consumption during adolescence enhanced basal levels of circulating leptin and induced protracted stress-induced release of glucocorticoids (Boitard et al., 2014; Boitard et al., 2015; Tantot et al., 2016). As leptin and glucocorticoids are important regulators of mesolimbic DA pathway and participate to amphetamine sensitization in lean animals (Fulton et al., 2006; Parnaudeau et al., 2014; Ferrario et al., 2016), it would be worthwhile to investigate the relationship between these hormonal changes and enhanced behavioral sensitization induced by pHFD. The enhanced sensitivity of the mesolimbic DA system induced by pHFD could impact reward processing. Whereas obesogenic diet consumption during adolescence decreases the motivation to work for rewards (Frazier et al., 2008; Vendruscolo et al., 2010; Naneix et al., 2016; Tantot et al., 2016), obesity is associated with specific enhancements of incentive properties of reward-related cues (Burger and Stice, 2011). The present study therefore highlights some neurobiological mechanisms which could support the increase incentive salience of food cues in obese patients. Given the increasing consumption of energy-rich foods in adolescents (Ogden et al., 2012), our results represent a step forward in the better understanding of the emergence of food-related disorders during development.

\section{References}

Adriani W, Laviola G (2004) Windows of vulnerability to psychopathology and therapeutic strategy in the adolescent rodent model. Behav Pharmacol 15:341-352. Medline

Andersen SL (2003) Trajectories of brain development: point of vulnerability or window of opportunity? Neurosci Biobehav Rev 27:3-18. Medline

Baladi MG, Horton RE, Owens WA, Daws LC, France CP (2015) Eating high fat chow decreases dopamine clearance in adolescent and adult male rats but selectively enhances the locomotor stimulating effects of cocaine in adolescents. Int $\mathrm{J}$ Neuropsychopharmacol 18:pyv024. CrossRef Medline

Berridge KC, Robinson TE (1998) What is the role of dopamine in reward: hedonic impact, reward learning, or incentive salience? Brain Res Brain Res Rev 28:309-369. Medline

Berthoud HR, Morrison C (2008) The brain, appetite, and obesity. Annu Rev Psychol 59:55-92. CrossRef Medline 
Boitard C, Cavaroc A, Sauvant J, Aubert A, Castanon N, Layé S, Ferreira G (2014) Impairment of hippocampal-dependent memory induced by juvenile high-fat diet intake is associated with enhanced hippocampal inflammation in rats. Brain Behav Immun 40:9-17. CrossRef Medline

Boitard C, Parkes SL, Cavaroc A, Tantot F, Castanon N, Layé S, Tronel S, Pacheco-Lopez G, Coutureau E, Ferreira G (2016) Switching adolescent high-fat diet to adult control diet restores neurocognitive alterations. Front Behav Neurosci 10:225CrossRef Medline

Boitard C, Maroun M, Tantot F, Cavaroc A, Sauvant J, Marchand A, Layé S, Capuron L, Darnaudery M, Castanon N, Coutureau E, Vouimba RM, Ferreira G (2015) Juvenile obesity enhances emotional memory and amygdala plasticity through glucocorticoids. J Neurosci 35:4092-4103. CrossRef Medline

Burger KS, Stice E (2011) Variability in reward responsivity and obesity: evidence from brain imaging studies. Curr Drug Abuse Rev 4:182-189. Medline

Campbell A, Villavicencio AT, Yeghiayan SK, Balikian R, Baldessarini RJ (1997) Mapping of locomotor behavioral arousal induced by microinjections of dopamine within nucleus accumbens septi of rat forebrain. Brain Res 771:55-62. Medline

Carlin JL, McKee SE, Hill-Smith T, Grissom NM, George R, Lucki I, Reyes TM (2016) Removal of high-fat diet after chronic exposure drives binge behavior and dopaminergic dysregulation in female mice. Neuroscience 326:170-179. CrossRef Medline

Chinen CC, Faria RR, Frussa-Filho R (2006) Characterization of the rapid-onset type of behavioral sensitization to amphetamine in mice: role of drug-environment conditioning. Neuropsychopharmacology 31:151-159. CrossRef Medline

Crews F, He J, Hodge C (2007) Adolescent cortical development: a critical period of vulnerability for addiction. Pharmacol Biochem Behav 86:189-199. CrossRef Medline

Cui G, Jun SB, Jin X, Pham MD, Vogel SS, Lovinger DM, Costa RM (2013) Concurrent activation of striatal direct and indirect pathways during action initiation. Nature 494:238-242. CrossRef Medline

Davis JF, Tracy AL, Schurdak JD, Tschöp MH, Lipton JW, Clegg DJ, Benoit SC (2008) Exposure to elevated levels of dietary fat attenuates psychostimulant reward and mesolimbic dopamine turnover in the rat. Behav Neurosci 122:1257-1263. CrossRef Medline

Décarie-Spain L, Hryhorczuk C, Fulton S (2015) Dopamine signalling adaptations by prolonged high-fat feeding. Curr Opin Behav Sci 9:136-146. CrossRef

Dobbs LK, Kaplan AR, Lemos JC, Matsui A, Rubinstein M, Alvarez VA (2016) Dopamine regulation of lateral inhibition between striatal neurons gates the stimulant actions of cocaine. Neuron 90:11001113. CrossRef Medline

Ferguson SM, Eskenazi D, Ishikawa M, Wanat MJ, Phillips PE, Dong Y, Roth BL, Neumaier JF (2011) Transient neuronal inhibition reveals opposing roles of indirect and direct pathways in sensitization. Nat Neurosci 14:22-24. CrossRef Medline

Ferrario CR, Labouèbe G, Liu S, Nieh EH, Routh VH, Xu S, O'Connor EC (2016) Homeostasis meets motivation in the battle to control food intake. J Neurosci 36:11469-11481. CrossRef Medline

Floresco SB, West AR, Ash B, Moore H, Grace AA (2003) Afferent modulation of dopamine neuron firing differentially regulates tonic and phasic dopamine transmission. Nat Neurosci 6:968-973. CrossRef Medline

Fordahl SC, Locke JL, Jones SR (2016) High fat diet augments amphetamine sensitization in mice: role of feeding pattern, obesity, and dopamine terminal changes. Neuropharmacology 109: 170-182. CrossRef Medline

Frazier CR, Mason P, Zhuang X, Beeler JA (2008) Sucrose exposure in early life alters adult motivation and weight gain. PLoS One 3:e3221. CrossRef Medline

Friend DM, Devarakonda K, O'Neal TJ, Skirzewski M, Papazoglou I, Kaplan AR, Liow JS, Guo J, Rane SG, Rubinstein M, Alvarez VA, Hall KD, Kravitz AV (2016) Basal ganglia dysfunction contributes to physical inactivity in obesity. Cell Metab 25:312-321.
Fulton S (2010) Appetite and reward. Front Neuroendocrinol 31:85103. CrossRef Medline

Fulton S, Pissios P, Manchon RP, Stiles L, Frank L, Pothos EN, Maratos-Flier E, Flier JS (2006) Leptin regulation of the mesoaccumbens dopamine pathway. Neuron 51:811-822. CrossRef Medline

Georges F, Aston-Jones G (2002) Activation of ventral tegmental area cells by the bed nucleus of the stria terminalis: a novel excitatory amino acid input to midbrain dopamine neurons. J Neurosci 22:5173-5187. Medline

Gerfen CR, Surmeier DJ (2011) Modulation of striatal projection systems by dopamine. Annu Rev Neurosci 34:441-466. CrossRef Medline

Glangetas C, Fois GR, Jalabert M, Lecca S, Valentinova K, Meye FJ, Diana M, Faure P, Mameli M, Caille S, Georges F (2015) Ventral subiculum stimulation promotes persistent hyperactivity of dopamine neurons and facilitates behavioral effects of cocaine. Cell Rep 13:2287-2296. CrossRef Medline

Grace AA, Bunney BS (1983) Intracellular and extracellular electrophysiology of nigral dopaminergic neurons-1. Identification and characterization. Neuroscience 10:301-315. Medline

Graybiel AM, Moratalla R, Robertson HA (1990) Amphetamine and cocaine induce drug-specific activation of the c-fos gene in striosome-matrix compartments and limbic subdivisions of the striatum. Proc Natl Acad Sci USA 87:6912-6916. Medline

Heusner CL, Hnasko TS, Szczypka MS, Liu Y, During MJ, Palmiter RD (2003) Viral restoration of dopamine to the nucleus accumbens is sufficient to induce a locomotor response to amphetamine. Brain Res 980:266-274. Medline

Ikemoto S (2002) Ventral striatal anatomy of locomotor activity induced by cocaine, D-amphetamine, dopamine and D1/D2 agonists. Neuroscience 113:939-955. Medline

Johnson PM, Kenny PJ (2010) Dopamine D2 receptors in addictionlike reward dysfunction and compulsive eating in obese rats. Nat Neurosci 13:635-641. CrossRef Medline

Kenny PJ (2011) Common cellular and molecular mechanisms in obesity and drug addiction. Nat Rev Neurosci 12:638-651. CrossRef Medline

Konradi C, Leveque JC, Hyman SE (1996) Amphetamine and dopamine-induced immediate early gene expression in striatal neurons depends on postsynaptic NMDA receptors and calcium. J Neurosci 16:4231-4239. Medline

Kravitz AV, Tye LD, Kreitzer AC (2012) Distinct roles for direct and indirect pathway striatal neurons in reinforcement. Nat Neurosci 15:816-818. CrossRef Medline

Labouesse MA, Lassalle O, Richetto J, lafrati J, Weber-Stadlbauer U, Notter T, Gschwind T, Pujadas L, Soriano E, Reichelt AC, Labouesse C, Langhans W, Chavis P, Meyer U (2016) Hypervulnerability of the adolescent prefrontal cortex to nutritional stress via reelin deficiency. Mol Psychiatry. Advance online publication. Retrieved Nov. 15, 2016. doi:10.1038/mp.2016.193.

Le Moine C, Bloch B (1995) D1 and D2 dopamine receptor gene expression in the rat striatum: sensitive cRNA probes demonstrate prominent segregation of D1 and D2 mRNAs in distinct neuronal populations of the dorsal and ventral striatum. J Comp Neur 355:418-426. CrossRef Medline

Liu S, Globa AK, Mills F, Naef L, Qiao M, Bamji SX, Borgland SL (2016) Consumption of palatable food primes food approach behavior by rapidly increasing synaptic density in the VTA. Proc Natl Acad Sci USA 113:2520-2525. CrossRef Medline

Mameli-Engvall M, Evrard A, Pons S, Maskos U, Svensson TH, Changeux JP, Faure P (2006) Hierarchical control of dopamine neuron-firing patterns by nicotinic receptors. Neuron 50:911-921. CrossRef Medline

McGuire BA, Baladi MG, France CP (2011) Eating high-fat chow enhances sensitization to the effects of methamphetamine on locomotion in rats. Eur J Pharmacol 658:156-159. CrossRef Medline

Naneix F, Darlot F, Coutureau E, Cador M (2016) Long-lasting deficits in hedonic and nucleus accumbens reactivity to sweet re- 
wards by sugar overconsumption during adolescence. Eur $\mathrm{J}$ Neurosci 43:671-680. CrossRef Medline

Naneix F, Marchand AR, Di Scala G, Pape JR, Coutureau E (2012) Parallel maturation of goal-directed behavior and dopaminergic systems during adolescence. J Neurosci 32:16223-16232. CrossRef Medline

Naneix F, Marchand AR, Pichon A, Pape JR, Coutureau E (2013) Adolescent stimulation of D2 receptors alters the maturation of dopamine-dependent goal-directed behavior. Neuropsychopharmacology 38:1566-1574. CrossRef Medline

Noble EE, Kanoski SE (2016) Early life exposure to obesogenic diets and learning and memory dysfunction. Curr Opin Behav Sci 9:714. CrossRef Medline

Norgren R, Hajnal A, Mungarndee SS (2006) Gustatory reward and the nucleus accumbens. Physiol Behav 89:531-535. CrossRef Medline

Ogden CL, Carroll MD, Kit BK, Flegal KM (2012) Prevalence of obesity and trends in body mass index among US children and adolescents, 1999-2010. JAMA 307:483-490. CrossRef

Oginsky MF, Maust JD, Corthell JT, Ferrario CR (2016) Enhanced cocaine-induced locomotor sensitization and intrinsic excitability of NAc medium spiny neurons in adult but not in adolescent rats susceptible to diet-induced obesity. Psychopharmacology (Berl) 233:773-784. CrossRef

Parnaudeau S, Dongelmans ML, Turiault M, Ambroggi F, Delbes AS, Cansell C, Luquet S, Piazza PV, Tronche F, Barik J (2014) Glucocorticoid receptor gene inactivation in dopamine-innervated areas selectively decreases behavioral responses to amphetamine. Front Behav Neurosci 8:35. CrossRef Medline

Parrot S, Neuzeret PC, Denoroy L (2011) A rapid and sensitive method for the analysis of brain monoamine neurotransmitters using ultra-fast liquid chromatography coupled to electrochemical detection. J Chromatogr B Analyt Technol Biomed Life Sci 879: 3871-3878. CrossRef Medline

Paus T, Keshavan M, Giedd JN (2008) Why do many psychiatric disorders emerge during adolescence? Nat Rev Neurosci 9:947957. CrossRef Medline

Paxinos G, Watson C (1998) The rat brain in stereotaxic coordinates, Ed 2. San Diego: Academic Press.

Reichelt AC (2016) Adolescent maturational transitions in the prefrontal cortex and dopamine signaling as a risk factor for the development of obesity and high fat/high sugar diet induced cognitive deficits. Front Behav Neurosci 10:189. CrossRef Medline

Robinson MJ, Burghardt PR, Patterson CM, Nobile CW, Akil H, Watson SJ, Berridge KC, Ferrario CR (2015) Individual differences in cue-induced motivation and striatal systems in rats susceptible to diet-induced obesity. Neuropsychopharmacology 40:21132123. CrossRef Medline

Robinson TE, Berridge KC (1993) The neural basis of drug craving: an incentive-sensitization theory of addiction. Brain Res Brain Res Rev 18:247-291. Medline

Schneider M (2013) Adolescence as a vulnerable period to alter rodent behavior. Cell Tissue Res 354:99-106. CrossRef Medline

Spear LP (2000) The adolescent brain and age-related behavioral manifestations. Neurosci Biobehav Rev 24:417-463. Medline
Steketee JD, Kalivas PW (2011) Drug wanting: behavioral sensitization and relapse to drug-seeking behavior. Pharmacol Rev 63: 348-365. CrossRef Medline

Tantot F, Parkes SL, Marchand AR, Boitard C, Naneix F, Layé S, Trifilieff $P$, Coutureau E, Ferreira G (2016) The effect of high-fat diet consumption on appetitive instrumental behavior in rats. Appetite 108:203-211. CrossRef Medline

Teegarden SL, Scott AN, Bale TL (2009) Early life exposure to a high fat diet promotes long-term changes in dietary preferences and central reward signaling. Neuroscience 162:924-932. CrossRef Medline

Ungless MA, Grace AA (2012) Are you or aren't you? Challenges associated with physiologically identifying dopamine neurons. Trends Neurosci 35:422-430. CrossRef Medline

Ungless MA, Whistler JL, Malenka RC, Bonci A (2001) Single cocaine exposure in vivo induces long-term potentiation in dopamine neurons. Nature 411:583-587. CrossRef Medline

Valjent E, Bertran-Gonzalez J, Aubier B, Greengard P, Hervé D, Girault JA (2010) Mechanisms of locomotor sensitization to drugs of abuse in a two-injection protocol. Neuropsychopharmacology 35:401-415. CrossRef

Valjent E, Pascoli V, Svenningsson P, Paul S, Enslen H, Corvol JC, Stipanovich A, Caboche J, Lombroso PJ, Nairn AC, Greengard P, Hervé D, Girault JA (2005) Regulation of a protein phosphatase cascade allows convergent dopamine and glutamate signals to activate ERK in the striatum. Proc Natl Acad Sci USA 102:491496. CrossRef Medline

Vanderschuren LJ, Kalivas PW (2000) Alterations in dopaminergic and glutamatergic transmission in the induction and expression of behavioral sensitization: a critical review of preclinical studies. Psychopharmacology (Berl) 151:99-120. Medline

Vanderschuren LJ, Schmidt ED, De Vries TJ, Van Moorsel CA, Tilders FJ, Schoffelmeer AN (1999) A single exposure to amphetamine is sufficient to induce long-term behavioral, neuroendocrine, and neurochemical sensitization in rats. J Neurosci 19:9579-9586.

Vendruscolo LF, Gueye AB, Darnaudéry M, Ahmed SH, Cador M (2010) Sugar overconsumption during adolescence selectively alters motivation and reward function in adult rats. PLoS One 5:e9296. CrossRef Medline

Volkow ND, Wang GJ, Baler RD (2011) Reward, dopamine and the control of food intake: implications for obesity. Trends Cogn Sci 15:37-46. CrossRef Medline

Wang GJ, Volkow ND, Thanos PK, Fowler JS (2009) Imaging of brain dopamine pathways: implications for understanding obesity. J Addict Med 3:8-18. CrossRef Medline

Wang GJ, Geliebter A, Volkow ND, Telang FW, Logan J, Jayne MC, Galanti K, Selig PA, Han H, Zhu W, Wong CT, Fowler JS (2011) Enhanced striatal dopamine release during food stimulation in binge eating disorder. Obesity (Silver Spring) 19:1601-1608. CrossRef

Wise RA (2006) Role of brain dopamine in food reward and reinforcement. Philos Trans R Soc Lond B Biol Sci 361:1149-1158. CrossRef Medline 